\title{
Fluxos passados e potencial de comércio internacional do Brasil por setores, 2000 a 2011
}

\author{
Elizama do Nascimento Oliveira Campos ${ }^{1}$ \\ Samuel Alex Coelho Campos ${ }^{2}$ \\ Fernanda Maria de Almeida ${ }^{3}$ \\ Marilia Fernandes Maciel Gomes ${ }^{4}$
}

\begin{abstract}
Resumo: Este artigo teve como objetivo analisar os determinantes do comércio internacional brasileiro por grupos de produtos (básicos, semimanufaturados e manufaturados) e verificar a ocorrência do potencial de comércio de 2000 a 2011 por meio de um modelo gravitacional com painel dinâmico. Os resultados indicaram uma relação positiva entre a renda brasileira e a renda do país importador, e dos fluxos passados de comércio sobre comércio, havendo ainda potencial de comércio a "ser explorado" nos setores de semimanufaturados e de manufaturados. Esses resultados indicam a necessidade de políticas comerciais para que os setores de manufaturados e de semimanufaturados obtenham ganhos de produtividade e de competitividade.
\end{abstract}

Palavras-chave: Comércio Internacional. Fluxos passados. Potencial de comércio. Modelo gravitacional.

Flow past and potential of international trade of Brazil by sector, 2000 at 2011

\begin{abstract}
This article aimed to analyze the determinants of Brazilian international trade by product groups (basic, semi-manufactured and manufactured) and to verify the occurrence of trade potential from 2000 to 2011 by a dynamic panel gravitational model. The results indicated a positive relationship between the Brazilian and the importing country income and the past trade flows on trade, and a potential for trade to be "exploited" in the semi-manufactured and manufactured sectors. These results
\end{abstract}

1 Doutoranda em Economia. Universidade Federal Fluminense - PPGE/UFF. Niterói, Rio de Janeiro. E-mail: elizamaoliveira@hotmail.com

2 Professor Adjunto do Departamento de Ciências Econômicas. Universidade Federal Fluminense, Instituto de Ciências da Sociedade e Desenvolvimento Regional - ESR/UFF. Campos dos Goytacazes, Rio de Janeiro, Brasil. E-mail: s.alex.coelho@gmail.com

3 Professora Adjunto do Departamento de Administração e Contabilidade. Universidade Federal de Viçosa - UFV. Viçosa, Minas Gerais, Brasil. E-mail: fernanda.almeida@ufv.br

4 Professora Associada do Departamento de Economia Rural - DER. Centro de Ciências Agrárias, Universidade Federal de Viçosa - UFV. E-mail: mfmgomes@ufv.br 
indicate the need for trade policies to enable the manufacturing and semi-manufactured sectors to gain productivity and competitiveness gains.

Keywords: International Trade. Past flows. Trade potential. Gravity model.

\section{Classificação JEL: F11, F13, F19}

\section{Introdução}

O comércio internacional é importante para o desenvolvimento econômico de um país, pois amplia a gama de produtos para consumo e eleva a produtividade, tornando-o mais competitivo. Segundo Wang, Wei e Liu (2010), o comércio bilateral desempenha um papel importante no crescimento financeiro, uma vez que promove economias de especialização, de concorrência, de escala e, também, incentiva a melhor alocação dos recursos produtivos.

A abertura comercial da década de 1990 permitiu que as negociações internacionais assumisse maior importância econômica para as nações, o que demandou a identificação dos fatores relacionados a esse comércio e ao seu crescimento e desenvolvimento (ALMEIDA; SILVA; CAMPOS, 2011; BAXTER; KOUPARITSAS, 2006; HELMERS; PASTEELS, 2005; KIM; CHO; KOO, 2003; LAI; ZHU, 2004; WANG; WEI; LIU, 2010;).

$\mathrm{O}$ conhecimento dos fatores associados às relações econômicas do comércio unilateral auxilia no entendimento e na ampliação dos fluxos comerciais e, consequentemente, na criação de novos consumidores. Almeida, Silva e Campos (2011) citam como fatores relacionados ao comércio o nível de produtividade de cada país exportador, as vantagens comparativas existentes na produção, a proporção empregada dos fatores de produção, a presença de economias de escalas e a ausência ou a existência de barreiras comerciais.

Wang, Wei e Liu (2010) ao analisarem os fatores influenciadores do comércio dos países da Organização para a Cooperação e Desenvolvimento Econômico (OCDE) identificaram que ações em Pesquisa e Desenvolvimento (P\&D) e em Investimento Direto Estrangeiro (IDE) também são importantes para a explicação dos fluxos do comércio.

Em outra análise sobre determinantes dos fluxos internacionais de comércio, Baxter e Kouparitsas (2006) indicam que, além das variáveis de gravidade padrão (distância, língua comum, comum fronteira, etc.) ${ }^{5}$, as dotações dos fatores de produção, o desenvolvimento econômico e as medidas de barreiras ao comércio, a

5 Variáveis gravitacionais básicas estão em modelos que utilizam equações de gravidade. Essas equações têm sido comumente utilizadas para explicar os fatores que determinam os fluxos bilaterais de comércio entre os países. 
volatilidade da taxa de câmbio, a união monetária e a semelhança da estrutura industrial explicam os fluxos de comércio entre pares de países.

Ademais, os fluxos passados de comércio são também relevantes, uma vez que podem influenciar o comércio presente. Diversos estudos têm justificado a introdução da variável defasada para explicar o comércio atual entre dois países. Antonucci e Manzocchi (2006) concluíram que o coeficiente da variável dependente defasada sugere que o comércio passado afeta, de fato, o atual. Bun e Klaassen (2002) destacaram que existem inúmeros argumentos econômicos que sugerem que o comércio é um processo dinâmico. Dentre outros estudos que também consideram esse caráter dinâmico do comércio destacam-se: Grauwe e Skudelny (2001), Martinez-Zarzoso, Felicitas e Horsewood (2009).

Todos os fatores mencionados, além de determinarem o comércio internacional, também se associam ao potencial de comércio entre as nações. Segundo Helmers e Pasteels (2005), o potencial de comércio é o resultado da capacidade de exportação e de importação dos países. Ele permite observar o nível de integração dos mercados, a existência de comércio "inexplorado" e a possibilidade de adoção de políticas comerciais para expansão do comércio.

O potencial de comércio entre as economias pode ser calculado pela diferença entre o que cada país tem a oferecer e o que querem em suas trocas internacionais. De acordo com Fonseca, Azevedo e Veloso (2005), a questão das estruturas de demanda e de oferta e do custo de transporte também é significativa. Contudo, não basta que as demandas sejam similares, é preciso que o parceiro em análise tenha capacidade de atendê-las e que seja competitivo de forma a compensar o custo de transporte (FONSECA; AZEVEDO; VELOSO, 2005).

Benedictis e Vicarelli (2005) e Shepotylo (2009) afirmam que para identificar o efetivo potencial de comércio existente entre os países é necessário considerar os fatores determinantes da demanda e da oferta, da resistência e das preferências, uma vez que o comércio potencial de um país está relacionado às suas características.

No caso do Brasil, pode-se dizer que as exportações e o grau de abertura da economia $^{6}$ têm importante papel para o desenvolvimento financeiro do país. O coeficiente de abertura da economia, entre 1990 e 2010, situou-se num patamar abaixo de $15 \%$ até o ano de 1999, seguindo uma trajetória progressiva até 2004, quando atinge seu pico de $24 \%$ e estabiliza-se em torno de $21 \%$ até 2008 devido ao crescimento do Produto Interno Bruto (PIB) acima da corrente de comércio nos anos de 2005 e 2006, e passou a apresentar uma trajetória de crescimento logo após o ano de 2009 (MDIC, 2012).

6 O grau de abertura da economia é medido pela participação da corrente de comércio (exportação + importação) em relação ao PIB. 
Entre os anos de 2000 e 2011, as exportações aumentaram cerca de $400 \%$, enquanto as importações cresceram em um percentual um pouco menor, aproximadamente, $350 \%$. Tais percentuais refletem a abertura comercial nos anos de 1990 concomitantemente a uma mudança geográfica no destino das exportações, caracterizando maior integração econômica regional (CASTILHO; LUPORINI, 2010; MDIC, 2012). O aumento dessas exportações também pode ser verificado em todos os grupos de produtos (básicos, manufaturados e semimanufaturados) ${ }^{7}$ ao longo desse período.

O principal grupo de produtos, em 2011, de acordo com o MDIC (2012), foram os básicos, que concentraram 47,82 \% das exportações, seguido dos produtos manufaturados e semimanufaturados, que representaram $36,04 \%$ e 14,07 $\%$ respectivamente.

Ao longo dos anos de 1990 a 2011 pode-se notar uma mudança na representatividade da pauta de exportação por setor. O setor de básicos cresceu consideravelmente ao longo desse período, enquanto o setor de semimanufaturas manteve-se estável e o de manufaturados apresentou queda nas exportações. Existe, também uma diferença notável entre os setores, visto que os produtos básicos acumularam crescimento de $41,1 \%$ entre 2005 e 2011 , ao mesmo tempo em que os produtos manufaturados exibiram uma queda $14,4 \%$ no período.

Analisar o potencial de comércio existente nos grupos de produtos básicos, semimanufaturados e manufaturados entre o Brasil e os seus principais parceiros comerciais é de suma importância, dado que essa análise pode possibilitar o aumento da integração econômica e o potencial de comércio não utilizado e, em adição, há a inexistência de estudos empíricos que utilizam essa abordagem. Essa análise permite o melhor entendimento da pauta de exportações brasileiras, bem como ações advindas dessa compreensão de modo a contribuir para a melhoria dessa pauta.

Devido a esse padrão de diversificação presente na pauta de exportações brasileiras, e a existência dos diferentes fatores que determinam esse comércio, buscou-se, neste trabalho, responder às seguintes perguntas: de que forma os fluxos passados, juntamente com as demais variáveis determinantes, influenciam no fluxo de comércio entre pares de países? Existe potencial de comércio "inexplorado" entre o Brasil e os seus principais parceiros comerciais para os produtos básicos, manufaturados e semimanufaturados?

7 O grupo de produtos básicos compreende os produtos de baixo valor agregado, como os produtos in natura, em sua maioria, e commodities agrícolas como café cru, soja, milho e carnes. O segundo grupo de produtos, os semimanufaturados, compreende os produtos como óleo de soja, couros e peles, alumínio, pastas químicas de madeiras, entre outros produtos de baixa e média intensidade tecnológica ou de menor processamento industrial. No grupo de produtos manufaturados encontram-se os produtos com maior nível tecnológico, como café solúvel, suco de laranja, vestuário, máquinas e equipamentos, entre outros produtos manufaturados de média e alta intensidade tecnológica. 
Tendo em vista o comportamento das exportações brasileiras, concentradas em alguns ${ }^{8}$ produtos e países e suas flutuações, o conhecimento dos determinantes do comércio existente entre o Brasil e os países parceiros, bem como o potencial de comércio entre eles é de significativa relevância. O conhecimento de fatores associados com mercados de elevada participação brasileira pode ser utilizado na expansão de setores de menor inserção. O conhecimento dos fatores relacionados negativamente à inserção brasileira pode auxiliar na formulação de políticas de expansão destes, fortalecendo o comércio e garantindo o crescimento econômico do Brasil.

Assim, este trabalho analisou as variáveis determinantes do comércio internacional brasileiro e identificou o potencial de comércio existente nas transações efetuadas nos três setores em análise: básicos, manufaturados e semimanufaturados, no período de 2000 a 2011.

Além desta introdução, este trabalho está estruturado em mais três seções e as considerações finais. No segundo capítulo, descreve-se brevemente a teoria geral do comércio internacional e a teoria do modelo gravitacional, ambas utilizadas como base neste artigo. $\mathrm{Na}$ terceira seção, aborda-se o método empírico e econométrico utilizado: dados em painel dinâmico e índice do potencial de comércio. Na quarta seção apresenta-se os principais resultados encontrados e então, as considerações finais.

\section{Referencial teórico}

Nesta seção é a apresentada a teoria do comércio internacional e a teoria do modelo gravitacional, ambas utilizadas na fundamentação teórica do trabalho.

\subsection{A teoria do comércio internacional}

O comércio internacional passou a ser modelado teoricamente por Adam Smith e David Ricardo e em seguida, pelo teorema de Heckscher-Ohlin. Pela teoria do comércio internacional, os países comercializam entre si por dois motivos principais: primeiro porque possuem recursos e, ou, tecnologias diferentes, o que os leva a se especializarem no que fazem melhor, e, segundo, para obterem retornos crescentes de escala.

De acordo Krugman e Obstfeld (2010), os modelos de comércio internacional podem ser vistos como casos específicos de um modelo mais geral, que descreve uma

8 Minério de ferro, petróleo bruto, complexo de soja, complexo de carnes, açúcar em bruto e café em grãos, produtos classificados como básicos na pauta exportadora brasileira, aumentaram sua participação no total das exportações de 28,4\% para 47,1\% entre 2006 e 2011 (BCB, 2012). 
economia mundial com comércio denominado Modelo Padrão de Comércio, que foi formulado com base nos modelos anteriores. O Modelo Padrão do Comércio é geral e mais realista, considera elementos como a dotação de fatores, que passam a ser determinantes do comércio internacional. Esse modelo tem como objetivo explicar o comércio internacional de forma mais abrangente. Nesse contexto, ele tem por base quatro características fundamentais: i) relação entre a fronteira de possibilidades de produção de um país e a curva de oferta relativa; ii) relação entre preços relativos e demanda relativa; iii) determinação do equilíbrio mundial pela oferta relativa e pela demanda relativa mundial; e iv) efeito dos termos de troca sobre o bem-estar da nação. A Figura 1 apresenta um esboço do modelo-padrão do comércio.

Figura 1. Produção, consumo e comércio no modelo-padrão

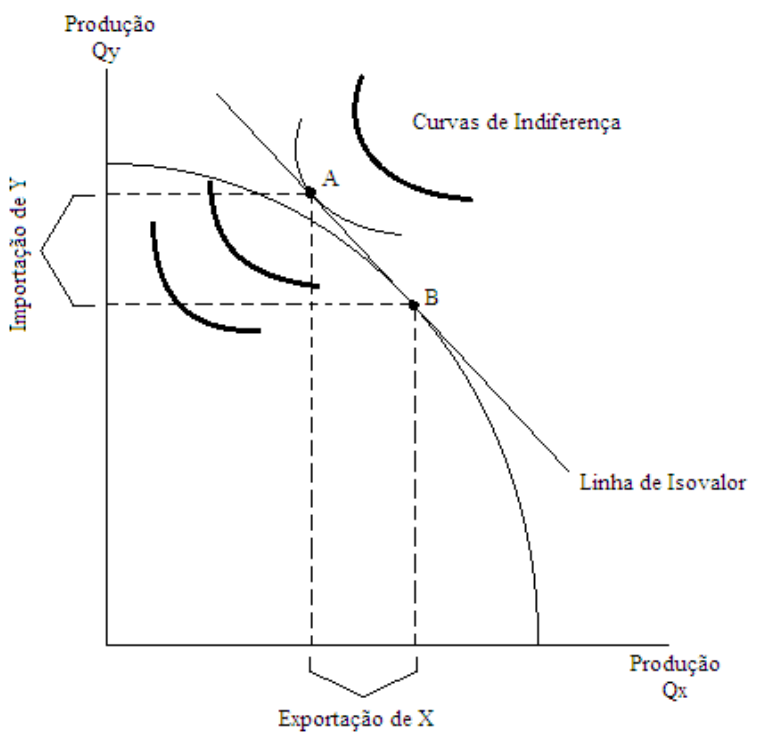

Fonte: Krugman e Obstfeld (2010).

A curva de possibilidades de produção tangenciada pela linha de isovalor determina a quantidade produzida na economia (ponto B). O consumo dessa economia é definido no ponto em que a curva de indiferença mais alta tangencia a linha de isovalor (ponto A). Assim, determinado setor ou país produz mais do bem X do que consome e, portanto, exporta o excedente, e produz menos do bem Y do que consome, importando o restante. Para determinar a oferta e a demanda mundial de um bem, baseia-se nas curvas de oferta e demanda doméstica do país exportador e importador, respectivamente. 
Desta forma, conduz-se a uma análise sobre o aspecto competitivo, levando o comércio internacional a ser influenciado por vários elementos, como taxas de câmbio, preços, estrutura de incentivos, barreiras tarifárias, entre outros fatores que podem influenciar nos fluxos de comércio de um país.

\subsection{O modelo gravitacional}

O modelo gravitacional surgiu da Lei de Gravitação Universal da Física. A utilização deste no âmbito econômico está baseada na força de atração com relação à massa e à distância entre objetos, sendo que a adaptação ao comércio se deu alicerçada na perspectiva de que o fluxo de comércio é função direta do produto de suas rendas e inversa da distância geográfica entre eles. De forma que, algebricamente, a formulação básica desse modelo, proposta por Anderson e van Wincoop (2003; 2004) pode ser exposta por:

$\ln F_{i j}=\beta_{0}+{ }_{i} \beta_{1} \ln Y_{i}+\beta_{2} \ln Y_{i}+\beta_{3} \ln Y_{i j}+e_{i j}$

em que, $\mathrm{F}_{\mathrm{ij}}$ representa o fluxo de comércio entre os dois países, $\mathrm{Y}_{\mathrm{i}}$ representa a renda do país $\mathrm{i}, \mathrm{Y}_{\mathrm{j}}$ representa a renda do país $\mathrm{j}, \mathrm{D}_{\mathrm{ij}}$ representa a distância entre esses dois países, $\beta$ 's são os parâmetros de cada variável, ln é o logaritmo neperiano e $\varepsilon_{i j}$ representa o termo do erro.

Os primeiros estudos que abordaram o modelo de comércio internacional incluindo a abordagem gravitacional datam da década de 1960, sendo o trabalho de Tinbergen (1962) pioneiro. Entretanto, as estimações de equações gravitacionais aplicadas ao comércio internacional nas décadas de 1960 e 1970 não apresentavam embasamento teórico, tendo esse modelo caído em descrédito, segundo Baldwin e Taglioli (2006). Em princípios da década de 1980, o modelo gravitacional era considerado fraco em relação à fundamentação da teoria econômica, com o surgimento de novas teorias do comércio passou a ter maior embasamento. Anderson (1979) introduziu microfundamentos para o modelo de gravidade baseando-se em propriedades dos sistemas de despesas e em pressuposições como diferenciação por origem.

Outros autores buscaram aprofundar o modelo seminal de gravidade baseados nas derivações de uma abordagem comercial, incluindo a diferenciação e a concorrência monopolística, desenvolvidas por Bergstrand (1989) e Helpman e Krugman (1985), por exemplo. Outra contribuição ao modelo advém do trabalho de Deardorff (1998), desenvolvendo em seu estudo uma abordagem da teoria de comércio de Heckscher-Ohlin em consistência com o modelo gravitacional. 
Diversos estudos têm incorporado novas variáveis ao modelo gravitacional básico para analisar o impacto de diferentes fatores sobre os fluxos de transações comerciais, debatendo estratégias teóricas e procedimentos para melhorar a precisão e a robustez dos modelos. Entre os principais trabalhos destacam-se aqueles desenvolvidos por Anderson (1979), Anderson e van Wincoop (2004), Bergstrand (1985) e Evennet e Keller (2002).

Anderson (1979) foi o primeiro a oferecer microfundamentos para o modelo de gravidade. Bergstrand (1985) buscou aprimorar a forma gravitacional generalizada em relação a trabalhos anteriores que refutavam o uso do modelo gravitacional na análise de bens de perfeita substituibilidade no comércio internacional e numa economia perfeita. De acordo com Kume e Piani (2000), a justificativa teórica mais utilizada para dar suporte ao modelo gravitacional remonta ao modelo de comércio desenvolvido por Krugman (1980), sob competição monopolística entre dois países, com a introdução de custos de transporte. Entretanto, o modelo considerado padrão foi o proposto por Anderson e van Wincoop (2003; 2004).

O modelo leva em consideração que os fluxos de comércio de um país podem ser influenciados por elementos como taxas de câmbio, preços, estrutura de incentivos, barreiras tarifárias, entre outros fatores. Anderson e van Wincoop (2004) consideram que a alocação do comércio entre os países pode ser analisada de forma separada da alocação da produção e do consumo dentro dos países. Esses autores destacam que o comércio entre dois países pode sofrer influências não apenas pela distância, mas também por uma barreira bilateral de comércio em relação à barreira média dos dois países com todos os seus parceiros comerciais.

\section{Metodologia}

Diante dos objetivos do estudo e da fundamentação teórica do modelo gravitacional exposta na seção anterior, foram incorporadas algumas variáveis relacionadas ao fluxo de comércio, tomando como base a Equação (1) para a estimação da Equação (2) na forma log-linear para cada setor, separadamente:

$\ln X_{i, t, t}=\beta_{0}+C r+\beta_{1} \ln Y_{i, t}+\beta_{2} \ln Y_{j, t}+\beta_{3} \ln D_{i j}+\beta_{4} \ln T X B R_{i, t}+\beta_{5} \ln T X_{j, t}+\beta_{6} \ln T_{i j, t}+\beta_{7} \ln X_{1, t, t-1}+\varepsilon_{1, j, t}$

em que $\mathrm{X}_{\mathrm{ij}, \mathrm{t}}$ são as importações do país i originadas do país $\mathrm{j}$ para o setores de produtos básicos, manufaturados e semimanufaturados, expressas em dólares no período t. São utilizadas as importações de cada país, em vez de as exportações, visto que os valores das exportações não são revistos se houver desistência entre os portos, o que viesaria as estimativas. Já os valores importados por país denotam o que foi efetivamente importado, ou, o que o Brasil efetivamente exportou; $\mathrm{Y}_{\mathrm{i}, \mathrm{t}}$ é o PIB do país 
i no período $t ; \mathrm{Y}_{\mathrm{j}, \mathrm{t}}$ é o PIB do país j no período t, que mensura o tamanho da economia na influência dos fluxos de comércio; e $\mathrm{Cr}$ é uma variável dummy adicionada para os anos de 2008/2009 a fim de captar os efeitos da crise do subprime; $\mathrm{D}_{\mathrm{ij}}$ é a distância entre os países i e j, uma proxy para os custos de transação não observáveis; $\mathrm{TxBR}_{\mathrm{j}, \mathrm{t}}$ é a taxa de câmbio brasileira, em Reais/Dólar; $\mathrm{TX}_{\mathrm{i}, \mathrm{t}}$ é a taxa de câmbio dos países importadores; $\mathrm{T}_{\mathrm{i}, \mathrm{t}, \mathrm{t}}$ ão as tarifas aplicadas ad valorem (calculadas com base no total dos valores importados) adicionadas como medida de resistência ao comércio; $\mathrm{X}_{\mathrm{ij}, \mathrm{t}-1}$ é variável do fluxo de comércio defasada em um período; $\varepsilon_{i j, t}$, o erro idiossincrático; e ln representa o logaritmo natural. Os dados são anuais e o período de análise foi de 2000 a 2011.

Esperou-se que o PIB per capita do país i e o PIB per capita do país j fossem positivos, pois quanto maior a renda do país, maior será sua capacidade de comércio. No que se refere à dummy adicionada para captar o efeito da crise 2008/2009, esperou-se que as exportações houvessem decrescido, apresentando, portanto, uma relação inversa entre as variáveis.

No que diz respeito à distância e as exportações, há uma relação inversa, uma vez que quanto maior a distância, supostamente, menor é o comércio. Acredita-se que a distância influencie negativamente as exportações via aumento de custos: quanto maior o custo, menor o volume esperado de comércio entre os países (HUMMELS, 2007).

Quanto à taxa de câmbio do país exportador (Brasil), esperou-se uma relação direta para as exportações, pois para uma dada desvalorização cambial o país exportaria mais pelo ganho de competitividade e pelo barateamento do produto nacional. Enquanto o inverso era esperado da taxa de câmbio dos países importadores, pois uma desvalorização cambial implicaria menores importações.

Para as tarifas aplicadas ad valorem, acreditou-se numa relação inversa, indicando que uma barreira ao comércio influencia negativamente as exportações. Para o fluxo defasado, quanto maior o histórico de parceiro comercial passado, maior tende a ser o comércio presente e futuro.

A escolha dos parceiros comerciais foi determinada pela importância que apresentavam no valor das exportações do país em 2011. Vale ressaltar que os 27 países selecionados representaram mais de $70 \%$ das exportações brasileiras dos setores no período em estudo.

\subsection{Estimação do modelo}

Com relação à técnica de estimação, dado que a variável dependente defasada (exportações com uma defasagem) foi incluída como explicativa, é utilizado, portanto, o painel dinâmico, como proposto por Arellano e Bover (1995) e Blundell e Bond 
(1998). De acordo com Greene (2003) a utilização de dados em painel apresenta inúmeras vantagens sobre os estudos convencionais de séries no tempo e seção cruzada, uma vez que eleva a quantidade de informação e os graus de liberdade. Apontam, ainda, que esse método é vantajoso pois reduz a multicolinearidade entre as variáveis explicativas, o que leva a uma maior eficiência das estimativas.

O painel dinâmico pode ser estimado por meio do método dos momentos generalizados (MMG), metodologia desenvolvida por Arellano e Bover (1995) e Blundell e Bond (1998). Esse modelo é alicerçado em um sistema de equações que assume como momento adicional a não existência de correlação entre o erro e o valor defasado para a variação da variável dependente defasada no primeiro período.

De acordo com Arellano e Bond (1991), a estimativa de um painel dinâmico deve conter todas as defasagens da variável dependente no modelo. Entretanto, segundo Perez e Truglia (2009), apesar da eficiência do método de estimação, ele apresenta problemas, uma vez que as primeiras diferenças usadas como instrumentos para equação de nível são fracamente exógenas, principalmente se a variável apresentar comportamento próximo a um passeio aleatório. O problema foi solucionado por Arellano e Bover (1995) e Blundell e Bond (1998) com a inclusão de uma restrição adicional, em que o termo de erro e a variável defasada não estão correlacionados, esse foi o modelo utilizado neste estudo.

A especificação econométrica para o modelo dinâmico (ver Equação 2), desenvolvida inicialmente por Arellano e Bond (1991), é embasada na suposição de que o comércio corrente tende a influenciar o desempenho do fluxo de comércio futuro. Isso explica a presença da variável dependente $\mathrm{X}_{\mathrm{i}, \mathrm{t}-1}$ defasada de um período do lado direito como variável explicativa na Equação (2).

Ao incluir a variável explicativa defasada no modelo (2), $\ln \mathrm{X}_{\mathrm{ij} t \mathrm{t}-1}$, pode-se incorrer em endogeneidade, uma vez que há uma variável explicativa estocástica correlacionada com o erro, ferindo assim uma das pressuposições do método de Mínimos Quadrados Ordinários (MQO).

Os modelos desenvolvidos por Arellano e Bover (1995), Blundell e Bond (1998) e outros posteriores buscaram corrigir pequenas falhas existentes no modelo inicial desenvolvido por Arellano e Bond (1991) e eliminar definitivamente o problema da endogeneidade. Com base nesses desenvolvimentos, surgiu o modelo de estimativa com dados em painel dinâmico, assumindo como momento adicional a não existência de correlação entre o erro e os valores passados, atuais e futuros das variáveis independentes.

Assim, a equação (2) deve ser reformulada em primeira diferença, que, estimada pelo Método dos Momentos Generalizados (MMG), dá origem ao Método dos Momentos Generalizados - Diferença (MMG-diferença). Considerando as 
pressuposições do modelo, foi estimada a equação (3) para a equação gravitacional na forma de painel dinâmico em primeira diferença:

$$
\begin{aligned}
& \ln \mathrm{X}_{\mathrm{ij,t}}=\beta_{0}+\mathrm{Cr}+\beta_{1} \ln \Delta \mathrm{Y}_{\mathrm{i}, \mathrm{t}}+\beta_{2} \ln \Delta \mathrm{Y}_{\mathrm{j}, \mathrm{t}}+\beta_{3} \ln \Delta \mathrm{D}_{\mathrm{ij}}+\beta_{4} \ln \Delta \mathrm{TXBR}_{\mathrm{i}, \mathrm{t}}+\beta_{5} \ln \Delta \mathrm{TX}_{\mathrm{i}, \mathrm{t}}+ \\
& \beta_{6} \ln \Delta \mathrm{T}_{\mathrm{i}, \mathrm{t}, \mathrm{t}}+\beta_{7} \ln \Delta \mathrm{X}_{\mathrm{i}, \mathrm{i}, \mathrm{-}-1}+\mathrm{e}_{\varepsilon \mathrm{ij, \textrm {t }}}
\end{aligned}
$$

em que $\Delta \ln [$ yit $]=\ln [$ yit $]-\ln [$ yit-1] para qualquer variável Yi,t.

Após a reformulação da equação (2) em (3), $\Delta \ln X_{i j, t-1}$ e $\Delta \varepsilon_{i j, t}$ serão correlacionados e, portanto, os estimadores de MQO para seus coeficientes serão viesados e inconsistentes. Logo, tem-se a necessidade de utilizar variáveis instrumentais para $\Delta \ln X_{i j, t-1}$. O conjunto de hipóteses adotadas no modelo (2) implicam que as condições de momentos $\mathrm{E}\left[\Delta \ln \left(X_{i j, t-s}, \Delta \varepsilon_{i j, t}\right)\right]=0$, para $\mathrm{t}$ $=3,4, \ldots, \mathrm{T}$ e $s \geq 2$ são válidas. Com base nesses momentos, Arellano e Bond (1991) sugerem empregar $\Delta \ln \left(X_{i j, t s}\right)$ para $\mathrm{t}=3,4, \ldots, \mathrm{T}$ e $s \geq 2$ como instrumentos para equação (3).

Com relação às outras variáveis explicativas do modelo, elas podem ser classificadas de três formas: (i) estritamente exógena, caso não seja correlacionada com os termos de erro passados, presentes e futuros; (ii) fracamente exógena, se for correlacionada apenas com valores passados do termo de erro; e (iii) endógena, se for correlacionada com os termos de erro passados, presente e futuros.

No caso (ii), os valores da variável defasados em mais de um período são válidos como instrumentos na estimação da equação (3). Já em (iii), os valores defasados em dois ou mais períodos são instrumentos válidos na estimação da equação (3). No entanto, Arellano e Bover (1995) e Blundell e Bond (1998) argumentam que esses instrumentos são fracos quando as variáveis dependentes e explicativas apresentam forte persistência e, ou, a variância relativa dos efeitos fixos aumenta, gerando um estimador não consistente e enviesado para painéis com $\mathrm{T}$ pequeno.

Para eliminar esse problema, Arellano e Bover (1995) e Blundell e Bond (1998) sugerem a estimação de um sistema que combine o conjunto de equações em diferenças: a equação (3), com o conjunto de equações em nível, e a equação (2), surgindo o método dos Momentos Generalizado-sistema (MMG-sistema). Para as equações em diferenças, o conjunto de instrumentos é o mesmo descrito acima na equação (3). Para equação em nível, os autores propuseram como instrumentos apropriados as diferenças defasadas das respectivas variáveis. Por exemplo, assumindo que as diferenças das variáveis explicativas não sejam correlacionadas com os efeitos fixos individuais (para $\mathrm{t}=3,4, \ldots, \mathrm{T})$ e $\mathrm{E}\left[\Delta \ln \left(\left(\mathrm{X}_{\mathrm{ij}, \mathrm{t}-\mathrm{s}}\right), \Delta \varepsilon_{\mathrm{ij}, \mathrm{t}}\right)\right]=0$, para $\mathrm{i}=1,2,3, \ldots, \mathrm{N}$, logo, as variáveis explicativas em diferenças e $\Delta \ln \left(\mathrm{X}_{\mathrm{i}, \mathrm{t}-1}\right)$, caso elas sejam exógenas ou fracamente exógenas, são instrumentos válidos para regressão em nível. $\mathrm{O}$ mesmo 
acontece se elas forem endógenas, mas os instrumentos se encontram na condição de variáveis explicativas em diferenças defasadas de um período mais $\Delta \ln \left(\mathrm{X}_{\mathrm{ij}, \mathrm{t}-1}\right)$.

A consistência do estimador MMG-sistema depende da suposição de ausência de correlação serial no termo de erro. Para tal, faz-se o teste de autocorrelação Arellano-Bond, dessa forma, inicialmente devem ser testadas as hipóteses nulas de ausência de autocorrelação de primeira e de segunda ordem dos resíduos. Para que os estimadores dos parâmetros sejam consistentes a hipótese de ausência de autocorrelação de primeira ordem deve ser rejeitada enquanto a autocorrelação de segunda ordem não pode ser rejeitada.

De acordo com Baldwin e Taglioni (2006), as equações do modelo gravitacional, que estudam os fluxos de comércio ao longo do tempo, devem incluir variáveis dummies para efeitos fixos, de forma a controlar os efeitos das variáveis ou as características não observadas entre os indivíduos e ao longo do tempo. Assim, a não inclusão dos efeitos fixos implicaria falha de especificação das equações gravitacionais e das estimativas viesadas.

Entretanto, Martinez-Zarzoso, Felicitas e Horsewood (2009) estimaram um modelo gravitacional utilizando o modelo de painel dinâmico proposto por Arellano e Bover (1995) e Blundell e Bond (1998) e consideraram que a inclusão das exportações defasadas nas regressões, como variável explicativa das exportações, permite controlar o componente tempo-invariante do termo da resistência multilateral (BALDWIN, 2006). Portanto, não seria necessária a inclusão de variáveis de efeitos fixos para o tempo para os países da amostra na regressão. Dessa forma, este trabalho não incluiu as dummies de efeitos temporais fixos. Destaca-se que o método de Arellano e Bover (1995) e Blundell e Bond (1998) ao utilizar a primeira diferença das variáveis controla os efeitos fixos ou as características fixas não observadas dos indivíduos. Assim, também não foram incluídas variáveis de efeitos fixos para os indivíduos.

Em geral, o modelo gravitacional é estimado para todos os pares de países e não somente para o Brasil como exportador. Porém, como o objetivo deste trabalho é mensurar as barreiras enfrentadas pelas exportações brasileiras, torna-se mais adequado considerar apenas o Brasil na forma de exportador e, assim, adotar uma análise unilateral. Essa abordagem foi adotada em diversos outros trabalhos, como o de Fassarela (2010), o de Karov et al. (2009) e o de Mata e Freitas (2008). Destacamse também Corrêa (2011), que analisou impactos das notificações ao acordo de barreiras técnicas nas exportações de produtos químicos do Brasil, e Alves (2012) que analisou o impacto das medidas não tarifárias na fruticultura brasileira. Ambos os autores estimaram o modelo com base no método Poisson Psendo-MaximumLikelihood (PPML), obtendo resultados de acordo com o esperado.

Quanto ao índice de potencial de comércio entre o Brasil e os seus principais parceiros, este foi calculado pelas estimativas encontradas do modelo gravitacional. 
Benedictis e Vicarelli (2005) argumentam que o modelo gravitacional é vantajoso, pois inclui determinantes da demanda e oferta, da resistência ao comércio, bem como dos fatores de preferências de comércio.

O potencial de comércio permite avaliar até certo ponto o nível de integração comercial entre os parceiros. Se houver uma diferença positiva, o comércio efetivo é maior que o previsto pelo modelo, supondo que o comércio tenha alcançado potencial favorável à maior integração futura, caso contrário (se for negativa a diferença), o comércio efetivo é menor que o previsto pelo modelo, indicando que precisa ser mais “explorado" entre esses países (BENEDICTIS; VICARELLI, 2005). O cálculo do potencial de comércio feito neste estudo seguirá a mesma forma funcional daquele utilizado por Almeida, Silva e Campos (2011) e Benedictis e Vicarelli (2005), expresso na seguinte equação:

$P_{i j, t}=\frac{\exp ^{W E_{i, t}}}{\exp ^{W \hat{E}_{i, t}}}$

em que $\mathrm{P}_{\mathrm{i}, \mathrm{t}}$ é o índice de potencial de comércio entre o país exportador i e o país importador $\mathrm{j}$ no período $\mathrm{t}$; $W E_{i j, t}$ são os valores observados das exportações dos setores em estudo; e $W \widehat{E}_{i j, t}$ são os fluxos de comércio estimados pela equação (3).

Padronizando os valores de $P_{i j, t}$ e reorganizando a equação, tem-se:

$$
I P_{i j, t}=\frac{P_{i j, t}-1}{P_{i j, t}+1}
$$

Dessa forma, os valores encontrados para o índice $I P_{i j, t}$ variam no intervalo entre -1 e +1 , de maneira que índices positivos indicariam que o comércio efetivo do produto é maior que o previsto pelo modelo, enquanto valores negativos mostram o contrário (ALMEIDA; SILVA; CAMPOS, 2011; BENEDICTIS; VICARELLI, 2005).

\subsection{Fonte e tratamento dos dados}

Quanto aos dados, os de importações foram obtidos no World Integrated Trade System-WITS, o PIB foi obtido no Banco Mundial (World Bank), e $\mathrm{D}_{\mathrm{ij}}$ no French Research Center in International Economics (CPII). As taxas de câmbio foram coletadas no site do Fundo Monetário Internacional - FMI. $T_{i j, t}$ no Market Access Map - MACMAP e no Trade Analysis and Information System -TRAINS. 
Tendo em vista a mudança notória na pauta de exportação brasileira depois dos anos 2000 descrita na introdução deste trabalho, em que o país passa a ter uma concentração na exportação de produtos básicos e uma redução da participação de bens manufaturados e semimanufaturados, a classificação por fator agregado foi adotada neste estudo. Essa classificação permite verificar se o comportamento na concentração de produtos básicos é condizente quando incluímos os fluxos passados, tal como quando calculamos a existência ou não de um potencial de comércio.

Vale ressaltar que os dados utilizados para os fluxos de comércio e para as tarifas, devido à maior confiabilidade e segurança dos dados, foram retirados respectivamente do World Integrated Trade Solution - WITS da United Nations Commodity Trade Statistics Database - UNCOMTRADE e do Market Access Map MACMAP e do Trade Analysis and Information System -TRAINS. Entretanto, esses sistemas não disponibilizam os dados por fator agregado (básicos, manufaturados e semimanufaturados), logo os grupos foram criados fundamentados na classificação disponível no MDIC (2012).

Os dados do WITS e MACMAP para o período em estudo (2000 - 2011) encontravam-se disponíveis, de forma desagregada, conforme a classificação Sistema Harmonizado de seis dígitos - SH6 de 1996. Entretanto, a versão disponibilizada pelo MDIC estava atualizada para o ano de 2012. Nesse caso, os dados por produto retirados das bases de dados internacionais foram atualizados e agrupados de acordo com a classificação do MDIC (2012). Isso permitiu a utilização da classificação definida sem que existissem defasagens de códigos e de descrições dos produtos, devido às mudanças ocorridas ao longo do período (1996 - 2012). Logo, permitiu-se a elaboração por fator agregado dada no trabalho em questão.

\section{Resultados e discussões}

Nesta seção são discutidos os resultados encontrados na estimação da regressão do modelo gravitacional, equação (3) e no índice de potencial de comércio equação (5).

\subsection{Determinantes do comércio internacional}

As variáveis distância e dummy para crise foram utilizadas como estritamente exógenas, pois elas não estariam correlacionadas com o termo de erro e não seriam determinadas simultaneamente com as exportações, isso considerando Baier e Bergstrand (2007) e Frankel e Romer (1999). As tarifas utilizadas como forma de capturar a facilitação do comércio foram incorporadas endogenamente, conforme Baier e Bergstrand (2007) e Martinez-Zarzoso, Felicitas e Horsewood (2009) que 
destacaram que acordos de comércio e políticas comerciais, de forma geral, seriam endógenas ao volume de exportação. O PIB foi considerado endógeno, conforme indicado por Frankel e Romer (1999), assim como as demais variáveis explicativas do modelo, uma vez que ou apresentam uma relação de simultaneidade entre as exportações, ou seja, existe uma relação bicausal entre as exportações e a variável, ou estão correlacionadas com o erro. Assim, como convencionalmente utilizado na metodologia, as variáveis consideradas endógenas foram instrumentalizadas por meio dos valores defasados delas mesmas.

Os resultados encontrados na equação gravitacional estimada podem ser observados na Tabela 1. Pelo teste de Wald pode-se verificar que as variáveis foram conjuntamente significativas em nível de $1 \%$ de significância.

O coeficiente do logaritmo dos fluxos passados apresentou significância estatística e sinal de acordo com a teoria para os três setores em estudo (básicos, manufaturados e semimanufaturados) indicando que, ceteris paribus, uma variação de $1 \%$ nos fluxos passados tende a aumentar os fluxos de comércio em 0,67\%, $0,82 \%$ e 0,62 \%, respectivamente para o grupo de produtos básicos, manufaturados e semimanufaturados.

Tabela 1 - Comparação dos valores dos coeficientes obtidos para o modelo gravitacional por setores, 2000 a 2011

\begin{tabular}{|c|c|c|c|c|}
\hline Variável & Sinal Esperado & Básicos & Manufaturados & Semimanufaturados \\
\hline $\ln X_{t-1}$ & Positivo $(+)$ & $0,67 * * *$ & $0,82 * * *$ & $0,62 * * *$ \\
\hline $\ln Y p$ & Positivo $(+)$ & $0,17 * * *$ & $0,11 *$ & $0,12 * * *$ \\
\hline $\ln Y b$ & Positivo $(+)$ & $0,49 * \cdots *$ & $0,20 * *$ & $0,45 \div \div \div$ \\
\hline $\ln T \mathrm{X}$ & Negativo (-) & 0,01 & $-0,03$ & $-0,03$ \\
\hline $\ln T x B R$ & Positivo $(+)$ & 0,34 & $0,43 * *$ & 0,21 \\
\hline $\ln \mathrm{T}$ & Negativo (-) & 2,56 & 1,54 & 0,86 \\
\hline $\mathrm{Cr}$ & Negativo (-) & $-0,08 *$ & $-0,10 * * *$ & $-0,19 * * *$ \\
\hline $\ln \mathrm{D}$ & Negativo (-) & 0,12 & $-0,32 * *$ & 0,29 \\
\hline
\end{tabular}

Fonte: Resultados de pesquisa.

Legenda: ***significativos a $1 \%$ de significância, ** significativo a $5 \%$ de significância, * significativo a 10 \% de significância.

Os resultados encontrados são similares aos obtidos por Jesus (2010), em que as defasagens do comércio para os produtos básicos indicaram que um aumento deste entre os países em períodos passados levou a um aumento do comércio no período atual, o que está de acordo com a teoria defendida, segundo a qual, o comércio é um processo dinâmico. Os resultados estão de acordo com Pinto (2011), em que as 
exportações defasadas exercem grande influência sobre o desempenho das exportações correntes, ao analisar a dinâmica e os determinantes das exportações totais brasileiras para economias asiáticas e da América Latina. Destarte, países que apresentam um bom desempenho exportador tendem a perpetuar este histórico positivo e aumentá-lo.

O resultado obtido está em consonância com as informações já citadas, ou seja, de que o comércio entre os países em períodos passados gera um aumento do comércio no período atual. Ademais, vale ressaltar que o conhecimento dos hábitos, das leis e dos costumes do parceiro no período atual leva a uma maior confiabilidade no futuro, implicando maiores fluxos de comércio entre as economias. Assim, podese verificar que, ao longo dos anos em estudo, há uma tendência de crescimento das exportações de produtos básicos e que, mesmo após a crise financeira e o fraco desempenho das economias desenvolvidas, o fluxo comercial do Brasil continuou em expansão devido à maior participação das commodities.

De maneira geral, e como esperado, os fluxos defasados de comércio confirmam as premissas de que o comércio internacional segue um processo dinâmico, assim as defasagens das exportações dos três setores influenciam positivamente as exportações presentes. Esse resultado indica que consumir produtos estrangeiros se torna um hábito para o consumidor final, assim como criar custos e barreiras à entrada e saída, à inserção de novos produtos e à comercialização com outros países. Assim, os países que já têm parcerias econômicas tendem a continuar o processo de comercialização.

O coeficiente para a variável $\ln (\mathrm{Yb})$ obteve estimativas condizentes com as expectativas para os três setores indicando que variações positivas da economia brasileira afetam positivamente os fluxos de comércio de produtos básicos, manufaturados e semimanufaturados para os principais parceiros econômicos. Portanto, um incremento de $1 \%$ na variação do PIB brasileiro tende a aumentar em $0,49 \%, 0,20 \%$ e $0,45 \%$ os fluxos de comércio entre as economias parceiras para os setores de produtos básicos, manufaturados e semimanufaturados, respectivamente. Esses resultados são coerentes com aqueles obtidos por Azevedo (2004) ao analisar os efeitos do Mercosul sobre o comércio.

A variável que representa o PIB do país importador $(\ln Y p)$ também foi significativa, individualmente para os três setores, estando o resultado de acordo com o esperado. Logo um aumento de $1 \%$ no PIB do país importador tende a aumentar em $0,17 \%, 0,11 \%$ e $0,12 \%$ as exportações brasileiras de produtos básicos, manufaturados e semimanufaturados, respectivamente.

A renda brasileira e a do país parceiro apresentaram comportamento positivo para todos os setores em estudo, destacando-se que a elasticidade do coeficiente é maior para o setor de produtos básicos. O aumento da participação do Brasil no mercado internacional entre 2000 e 2010 se deve, sobretudo, ao setor de produtos 
básicos e, em grande parte, à maior participação da China. É importante ressaltar a participação de outros países que também se destacaram como importadores de produtos básicos do Brasil: os EUA, a Alemanha, o Japão, a Espanha, a França e a Holanda que somaram cerca de $60 \%$ das exportações brasileiras no período em questão (MDIC, 2012).

As taxas de câmbio do Brasil e do país importador não foram significativas individualmente para explicar as exportações de produtos básicos e semimanufaturados. A pouca variação da moeda dos países parceiros durante o período pode ter resultado em coeficientes não significativos para os grupos de produtos em estudo. Pode-se levar em consideração a pequena sensibilidade às variações no consumo desses produtos, uma vez que são bens essenciais, portanto, de baixa elasticidade preço.

Observou-se ainda que as exportações de manufaturas foram mais sensíveis às variações na taxa de câmbio brasileira. Era o que se esperava, dado que as elasticidades do câmbio de produtos manufaturados são superiores aos produtos básicos e semimanufaturados pelo fato de que a necessidade destes é menor. Esse resultado indica a importância e a sensibilidade das exportações em relação ao câmbio para os produtos manufaturados, tendo sido similar ao encontrado por Zimmermann (2012) ao estudar o comportamento da taxa de câmbio para as exportações de produtos de alta intensidade tecnológica.

Em geral, o coeficiente da variável tarifa aplicada adicionada como medida de resistência ao comércio não foi individualmente significativa para explicar as exportações nos três setores em estudo. Esse comportamento pode estar associado ao fato de os produtos estarem agregados e as exportações dos setores estarem concentradas em poucos produtos. Outros autores também encontraram resultados similares, como Bittencourt (2013) que encontrou sinal negativo e não significativo para o coeficiente de tarifa do setor agrícola, indicando que as exportações/importações de produtos básicos são pouco sensíveis a tarifas comerciais. Destaca-se, ainda, a ausência de significância estatística para variável tarifa, indicando que esta não possui efeito sobre os fluxos de comércio dos países em estudo.

Resultados negativos e não significativos das tarifas são contrários à teoria do comércio internacional que aponta tarifas como barreiras comerciais. No entanto, a maior participação do Brasil no comércio mundial ao longo do tempo impulsionou o aumento substancial do consumo do produto e isso, certamente, fez com que os efeitos negativos das tarifas fossem superados. Como destacado por Almeida (2012), as rodadas de negociações internacionais de comércio têm buscado a redução do uso das tarifas, dando espaço para o uso de medidas técnicas ao comércio. Os efeitos das tarifas estatisticamente iguais a zero podem ser resultado da pouca utilização dessas medidas no comércio dos produtos. Anderson e van Wincoop (2004), em um estudo 
sobre os custos incidentes sobre o comércio, encontraram um coeficiente muito pequeno para as tarifas sobre o fluxo de comércio. Porém, eles enfatizaram a importância das tarifas nos dias atuais e recomendam a permanência dessa variável no modelo para evitar que outras captem o efeito da sua omissão.

A dummy adicionada para captar os efeitos da crise de 2008/2009 também foi significativa nos três grupos de produtos, indicando que todos os setores foram afetados pela crise econômica, porém o setor de produtos básicos, como esperado, foi menos impactado pela crise. De acordo com o coeficiente obtido, é possível denotar que a crise implicou redução nos fluxos de comércio entre o Brasil e os seus parceiros em $8,3 \%, 9,5 \%$ e $17,3 \%{ }^{9}$, para os setores de produtos básicos, manufaturados e semimanufaturados, respectivamente.

Por fim, ressalta-se que o coeficiente da variável distância $\ln \mathrm{D}$, utilizada como proxy para os custos de transporte foi significativo e com sinal negativo apenas para o grupo de produtos manufaturados. A não influência da distância sobre as exportações dos produtos básicos e semimanufaturados pode estar relacionada à elevada representatividade do país nesses setores - principalmente nos produtos básicos -, à maior competitividade e à dependência de alguns países, como a China, para o minério de ferro brasileiro. A não significância também pode estar associada ao fato de que países como Peru, Argentina e Bolívia, apesar de estarem entre os principais parceiros econômicos do Brasil, não se destacam como os maiores importadores destes produtos. Embora estejam geograficamente próximos, os maiores volumes de exportação foram direcionados para países mais distantes, como para China, no caso de produtos básicos. O mesmo não acontece com o grupo de manufaturados, uma vez que os maiores fluxos de comércio foram destinados à Argentina, país que tem fronteira com o Brasil, o que justifica a significância estatística e o sinal negativo como aponta a teoria internacional do comércio.

Destaca-se que a renda brasileira e a renda do país importador são fortes determinantes para as exportações de produtos básicos, manufaturados e semimanufaturados, que as exportações passadas confirmam as hipóteses de que o comércio internacional segue um processo dinâmico e que as defasagens das exportações dos três setores influenciam positivamente as exportações presentes.

A consistência do estimador MMG-sistema depende da suposição de ausência de correlação serial no termo de erro. Dessa forma, foram testadas as hipóteses nulas de ausência de autocorrelação de primeira e de segunda ordem dos resíduos. Para que os estimadores dos parâmetros sejam consistentes a hipótese de ausência de autocorrelação de primeira ordem deve ser rejeitada, enquanto a hipótese para ausência de correlação de segunda ordem não. A Tabela 2 mostra que os resultados do

9 O efeito percentual da variável binária foi calculado conforme proposto por Halvorsen e Palmquist (1980): $100 *[\exp (\mathrm{Cr})-1]$. 
teste de autocorrelação de Arellano-Bond não rejeitam a hipótese nula de ausência de autocorrelação de segunda ordem, mas rejeitam a autocorrelação de primeira ordem, para todos os setores, indicando, assim, que os coeficientes estimados são consistentes.

Tabela 2 - Teste de autocorrelação, 2000 a 2011

\begin{tabular}{ccccccc}
\hline & \multicolumn{2}{c}{ Básicos } & \multicolumn{2}{c}{ Manufaturados } & \multicolumn{2}{c}{ Semimanufaturados } \\
\hline Ordem & Estatística $\mathbf{z}$ & Probabilidade & $\begin{array}{c}\text { Estatística } \\
\mathbf{z}\end{array}$ & Probabilidade & $\begin{array}{c}\text { Estatística } \\
\mathbf{z}\end{array}$ & Probabilidade \\
\hline 1 & & & & 0,00 & $-2,80$ & 0,01 \\
2 & 1,14 & 0,01 & $-3,11$ & 0,16 & 0,97 & 0,33 \\
\hline
\end{tabular}

Fonte: Resultados de pesquisa.

\subsection{Potencial de comércio por setores}

Quanto aos índices de potencial de comércio, estes foram calculados para os três setores em estudo (básicos, manufaturados e semimanufaturados) e para todos os parceiros comercias da amostra, entre 2001 e 2011. Os resultados estão em médias para os anos em estudo e apresentados na Tabela 3, para os setores de produtos básicos, manufaturados e semimanufaturados.

Tabela 3 - Comparação dos valores médios para o índice do potencial de comércio por país e setor, 2001 a 2011

\begin{tabular}{cccc}
\hline País/Setor & Básicos & Manufaturados & Semimanufaturados \\
\hline Argentina & $-0,06$ & $-0,05$ & 0,25 \\
Bélgica & 0,02 & 0,06 & 0,01 \\
Bolívia & $-0,24$ & $-0,03$ & $-0,43$ \\
Canadá & $-0,25$ & 0,00 & 0,05 \\
Suíça & $-0,19$ & $-0,10$ & $-0,14$ \\
Chile & 0,08 & 0,05 & 0,01 \\
China & 0,39 & 0,08 & 0,17 \\
Colômbia & $-0,22$ & 0,07 & $-0,01$ \\
Alemanha & 0,11 & 0,04 & 0,07 \\
Argélia & 0,00 & $-0,10$ & 0,10 \\
Espanha & 0,06 & $-0,05$ & $-0,07$
\end{tabular}




$\begin{array}{cccc}\text { Continuação } & 0,02 & -0,05 & -0,05 \\ \text { França } & -0,04 & -0,03 & -0,18 \\ \text { Reino Unido } & 0,10 & -0,04 & -0,09 \\ \text { Índia } & 0,01 & -0,07 & 0,08 \\ \text { Itália } & 0,06 & 0,06 & 0,03 \\ \text { Japão } & 0,34 & 0,09 & 0,08 \\ \text { Coréia do Sul } & -0,19 & 0,03 & -0,01 \\ \text { México } & -0,11 & -0,03 & 0,00 \\ \text { Malásia } & 0,06 & 0,16 & 0,15 \\ \text { Nigéria } & 0,15 & 0,04 & -0,01 \\ \text { Holanda } & -0,07 & -0,03 & -0,18 \\ \text { Peru } & 0,17 & -0,01 & 0,09 \\ \text { Rússia } & 0,09 & 0,02 & -0,06 \\ \text { Arábia } & -0,22 & -0,11 & 0,04 \\ \text { Uruguai } & -0,01 & 0,04 & 0,24 \\ \text { Estados Unidos } & -0,08 & -0,05 & -0,13 \\ \text { Venezuela } & & \text { Fonte: Resultados } & \end{array}$

Fonte: Resultados da pesquisa.

Os índices de potencial de comércio apresentam valores entre - 1 e +1 , como calculado pela equação (5). Verifica-se que, ao longo dos anos de estudo, para os setores e para os países da amostra há uma estabilidade nos valores encontrados dos índices de potencial de comércio. Esse resultado é similar aos obtidos por Almeida, Silva e Campos (2011) quando analisaram o potencial de comércio para a soja. Assim, para cada país importador e por setor, os índices tendem a permanecer ou positivos ou negativos ao longo dos anos da amostra. Se o índice for positivo, o comércio observado supera o estimado pelo modelo, ou seja, o comércio potencial do setor em questão é maior que o comércio atual entre os países.

Tendo em vista que o Brasil é um dos principais países exportadores de produtos básicos, no período em estudo os valores obtidos para os índices de potencial de comércio foram positivos para grande parte dos parceiros, entre eles, China, Alemanha, Espanha, França, Japão, Holanda, Coréia do Sul, Chile e Rússia, como esperado. Esse comportamento indica que o país apresentou sucesso na parceria para esse setor, uma vez que este é o de maior representatividade na pauta de exportação brasileira. 
Segundo MDIC (2012), os EUA, a China, a Alemanha, o Japão, a Espanha, a França e a Holanda somaram, em conjunto, cerca de $60 \%$ das exportações brasileiras de produtos básicos, no período de 2000 a 2011, reforçando os resultados ora obtidos que sinalizam a existência de um maior grau de integração comercial entre esses países e o Brasil para o setor.

Entre 2001 e 2011, os produtos básicos dominaram a pauta de exportações brasileiras contribuindo para manter superavitária a balança comercial do país, fator relevante para a maior integração comercial desses produtos com os parceiros comerciais em estudo. Destaca-se também a participação da China e da Rússia, países pertencentes ao BRICS, com índices de potencial de comércio positivos.

Vale ressaltar a mudança desse índice para alguns países ao longo dos anos em estudo, assim como a sua oscilação no período em questão. Destaca-se a mudança no potencial de comércio da Nigéria, de negativo para positivo, que pode estar associada a uma maior exportação de produtos básicos, em termos de porcentagem, para esses países na década de 2000. O percentual máximo de variação das exportações de produtos básicos foi de $323 \%$ para Nigéria, enquanto o potencial de comércio do Peru se reduziu (de positivo para negativo)indicando que seu comércio passou a ser explorado em meados da década de 2000. Esse comportamento pode ser atribuído à maior produção interna de produtos desse setor, ou até mesmo à diversificação de parceiros comerciais, que aumentaram seu percentual nas exportações para esse país.

O potencial de comércio a ser explorado entre os países da amostra e o Brasil pode ser verificado pelos índices negativos obtidos ao longo do período, indicando que pode haver maior integração comercial com alguns países, entre eles, Canadá, Bolívia, Suíça, Colômbia, Uruguai e Argélia. Ou seja, existe um potencial de comércio a ser explorado com o Brasil. Canadá e Argélia têm como principal parceiro comercial a China, um grande produtor e exportador de produtos básicos que compete com o Brasil. Dessa forma, a existência de uma integração comercial desfavorável entre o Brasil e o Canadá e a Argélia pode ser justificada pelo fato de esses países comercializarem com a China.

Existe a necessidade de políticas comerciais entre esses países que favoreçam um comércio com o Brasil. Os valores positivos obtidos para a maioria dos países, como esperado para esse setor, indicam que o comércio unilateral tem uma integração favorável.

$\mathrm{Na}$ análise do potencial de comércio para os produtos manufaturados em comparação com o grupo de produtos básicos, como esperado, há menor prevalência de valores positivos para os índices. É importante observar que nesse setor existe uma grande diversificação entre os valores dos índices encontrados, entretanto, percebe-se um maior número de índices negativos, indicando que o comércio como um todo ainda pode ter um incremento nas vendas. Entre os índices positivos encontrados, 
como esperado, destacam-se aqueles dos EUA e da Argentina, os principais países de destino dessas exportações, que responderam em torno de $35 \%$ das exportações brasileiras para o ano de 2011.

Os resultados permitem concluir que há maior grau de integração comercial entre esses países e o Brasil no setor de produtos manufaturados. Entre os anos em análise destacam-se também os índices positivos para Argentina, resultados condizentes com os esperados, uma vez que países geograficamente próximos ao Brasil constituem um fator facilitador do comércio. Considerando que no modelo gravitacional a distância é fator de influência negativa, enquanto a fronteira comum é fator de influência positiva ao comércio, os índices de potencial de comércio positivos para os países mais próximos são condizentes com o maior grau de integração comercial. Ressalta-se também a presença de índices muito próximos a zero ou que variam muito ao longo dos anos, ora positivos, ora negativos.

Há também um terceiro grupo de países da amostra em que predomina a negatividade dos índices de potencial do comércio, casos do Reino Unido, da Itália e do Uruguai, países com necessidade de maior integração comercial para o setor de produtos manufaturados.

O índice de potencial de comércio para os produtos semimanufaturados indicou, de forma geral, que para esse setor o comércio unilateral efetivo é menor que o previsto pelo modelo para a maioria dos parceiros comerciais analisados, para o período de 2001 a 2011. Esse valor indica potencial de comércio não explorado, necessidade de promoção das exportações e de maior integração comercial.

Os principais destinos das exportações brasileiras de semimanufaturados, entre 2001 e 2011, foram os Estados Unidos da América, seguidos da China, da Holanda, do Japão, da Itália, da Rússia e da Bélgica, que, juntos, somaram mais de $80 \%$ das exportações do setor. Dessa forma, eram esperados valores positivos para o índice entre esses países, ou seja, que esse índice mostrasse que o Brasil teria sucesso na integração comercial com os outros países. Entretanto, os índices para Estados Unidos, Holanda, Itália e Bélgica foram negativos, ou seja, apesar de serem países de elevada integração e apresentarem participação significativa nas exportações, ainda há comércio não explorado com estes, com possibilidade de maior integração comercial e necessidade de promoção das exportações.

De acordo com os resultados obtidos para o potencial de comércio nesse setor, Argentina, Canadá, China e EUA apresentam integração comercial positiva, não significando que o Brasil não necessite aumentar sua integração com esses países, pois os índices encontrados não ultrapassam 0,4, distante do limite de 1, como os países apresentados no setor de produtos básicos, que apresentaram elevada integração comercial. Destaca-se que, apesar de esses países apresentarem possibilidade de maior integração comercial, há um elevado potencial não explorado para os países do 
Mercosul (Bolívia, Peru e Venezuela) que deve ser observado. Os índices negativos obtidos para estes podem ser justificados por serem produtores e exportadores de semimanufaturas para o Brasil, indicando que entre eles existe uma competição de mercado em termos de produção e exportação. Entretanto, ressalta-se que a promoção de mais exportações desse setor pode ser uma estratégia importante de diversificação dos parceiros comerciais, uma vez que a pauta de exportação é concentrada em poucos países.

Ademais, nesse setor, o Brasil apresenta elevado comércio não explorado com outros países que apresentam menor importância nas exportações, como Venezuela, Espanha, França, Reino Unido e México. Estes, apesar de estarem entre os principais parceiros comerciais do Brasil, não se destacam como grandes importadores de produtos semimanufaturados, mas, na sua grande maioria, como importadores de produtos básicos e manufaturas. O comportamento da Venezuela pode ser entendido como resultado da crise de alimentos e hiperinflação que o país vive, principalmente pelo controle de preços estabelecido em 2003 pelo governo, que impôs cotas de produção para determinados alimentos. Dessa forma, o país tende a comercializar mais produtos básicos que manufaturas ou semimanufaturas.

Os resultados encontrados para os índices de potencial desse setor confirmam o argumento de que o desempenho das exportações de semimanufaturados se deve a problemas de competitividade do país, o que acabaria por estreitar o foco do diagnóstico em dois pontos principais: política cambial e fatores estruturais que afetam o custo das empresas (GAP, 2012). Ademais, mesmo em um cenário benéfico à indústria brasileira, ela enfrenta problemas de competitividade, que limitam a capacidade de exportação desses produtos.

A comparação dos valores permite perceber facilmente que, de forma geral, todos os setores apresentaram baixo potencial de comércio para a maior parte dos países. Entretanto, na prevalência de média de índices positivos, o setor de produtos básicos apresentou uma maior elevação, ou seja, mais próximos de 1, enquanto os demais setores apresentaram valores próximos a zero. Ou seja, o senso comum de que o país é um grande exportador de produtos básicos com sucesso nas parcerias comerciais foi confirmado.

Assim, em geral, os resultados encontrados confirmam as premissas de que o Brasil obtém sucesso na parceria para o setor de produtos básicos e que, em geral, há um potencial de comércio inexplorado nos setores de produtos semimanufaturados e manufaturados para a maioria dos parceiros comerciais da amostra. Tal resultado indica que há uma necessidade de maior integração.

O Brasil apresentou integração comercial para o grupo de produtos manufaturados e semimanufaturados de modo semelhante. $O$ setor de semimanufaturados apresentou valores maiores dos índices de potencial de comércio, 
apesar de representar, em média, $14 \%$ do total exportado ao longo da década de 2000 , enquanto a participação do setor de manufaturados foi, em média, de $54 \%$. Esse comportamento pode ser explicado pelo fato de o setor de manufaturados compreender mais etapas de produção, "acumulando" ineficiências competitivas ao longo de todo o processo de produção, portanto, menos competitivo quando comparado ao setor de semimanufaturados. Dessa forma, há necessidade de políticas comerciais específicas para os dois últimos setores em estudo.

\section{Considerações finais}

O comércio internacional possibilita ganhos de eficiência, economias de escala, aumento da competição e, consequente, redução de preços, ampliando a variedade de produtos para consumo e melhorando o processo de produção dos países parceiros.

Assim, conhecer os fatores associados às relações econômicas do comércio internacional auxilia no entendimento e na ampliação dos fluxos comerciais e, consequentemente, na criação de novos consumidores.

Portanto, este trabalho vem contribuir para a ampliação de conhecimento, visto que analisou o caráter dinâmico do comércio unilateral entre Brasil e seus parceiros, bem como verificou se existe um potencial de comércio "inexplorado" entre os pares de países por setores básicos, manufaturados e semimanufaturados. A análise compreendeu o período de 2000 a 2011.

Em geral, as relações estimadas para os três setores por meio da equação gravitacional foram significativas e associadas ao fluxo do comércio conforme esperado. Destacaram-se como principais variáveis relacionadas a esse fluxo de comércio, para todos os setores analisados, os fluxos passados de comércio, a renda brasileira e a renda do país importador.

Enfatiza-se que, enquanto a crise financeira de 2008 afetou negativamente as economias desenvolvidas, o fluxo comercial do Brasil continuou em expansão, devido à maior participação das commodities na sua pauta de exportações.

O histórico do comércio, aqui representado pelas exportações no ano anterior, apresentou relação conforme esperado. Os coeficientes estimados foram significativos e positivos para todos os setores analisados. Esses resultados indicam a importância de parcerias para o comércio internacional e a presença de uma "inércia” no fluxo de comércio, ou seja, quanto maior o fluxo passado, maior tende a ser o comércio futuro.

Apesar de as medidas tarifárias serem determinantes no comércio, de forma geral, no período em estudo essas variáveis não foram significativas individualmente, sendo que outras variáveis, como a renda, tiveram maior importância para as exportações, restringindo e compensando o efeito individual dessas variáveis. 
Quanto ao potencial de comércio calculado para cada país parceiro do Brasil e para cada setor, ele indicou baixo potencial de comércio a ser explorado para o setor de produtos básicos para a maior parte dos países. Esse resultado indica que o país é um grande exportador de produtos básicos com sucesso nas suas parcerias comerciais.

O potencial de comércio para os setores de semimanufaturados e manufaturados apresentou comportamento esperado. Primeiramente, o potencial de comércio não "explorado", em média, dos manufaturados, foi maior que o dos semimanufaturados, indicando que nesse último setor o país apresenta uma integração comercial mais favorável do que no de manufaturados. Os resultados indicam que o Brasil tem sucesso maior na comercialização de semimanufaturados comparativamente a manufaturados.

De forma geral, o Brasil obteve sucesso na parceria comercial para o setor de produtos básicos, enquanto para os setores de produtos semimanufaturados e manufaturados há uma integração comercial não favorável na maioria dos parceiros comerciais analisados, havendo necessidade de maior integração comercial.

Pelo observado, conclui-se pela necessidade de políticas comerciais específicas para o setor de produtos manufaturados e para o setor de semimanufaturados que incentivem a adoção de novas tecnologias no processo produtivo, inovação e ganhos de produtividade e, também, políticas de redução dos tributos, de modo a ampliar o fluxo de comércio desses setores. Também são necessárias políticas que estimulem o crescimento e a competitividade no setor industrial, de forma que a política industrial esteja em consonância com a política de comércio exterior. Esse acordo entre essas políticas é essencial para impulsionar o setor exportador industrial, bem como a combinação de política fiscal, de forma a incentivar investimentos na produção e ganhos de produtividade e competitividade.

\section{Referências}

AlMEIDA, F. M.; SILVA, O. M.; CAMPOS, A.C. Potencial de comércio no mercado internacional de trigo. Pesquisa E Debate, São Paulo, v. 22, n. 1, p. 189-208, 2011.

ALMEIDA, F. M. Medidas não tarifárias e comércio internacional agrícola: os efeitos dos objetivos das notificações aplicadas aos acordos TBT e SPS. 2012. 129f. Tese (Doutorado em Economia Aplicada) - Universidade Federal de Viçosa, Viçosa - MG, 2012.

ALVES, G. J. Impacto de medidas não tarifárias na fruticultura brasileira. 2012. $101 \mathrm{f}$. Dissertação (Mestrado em Economia Aplicada) - Universidade Federal de Viçosa, Viçosa - MG, 2012. 
ANDERSON J.E. A Theoretical foundation for the gravity equation. The American Economic Revierw, v. 69, n.1, p.106-116, 1979.

ANDERSON, J.E.; van WINCOOP, E. Gravity with gravitas: a solution to the border puzzle. American Economic Review, Nashville, v. 93, n. 1, p. 170-192, 2003. DOI: https://doi.org/10.1257/000282803321455214

ANDERSON, J.E.. Trade costs. Journal of Economic Literature, v. 42, n. 3, p. 691751, 2004. DOI: https://doi.org/10.1257/0022051042177649

ANTONUCCI, D.; MANZOCCHI, S. Does Turkey have a special trade relation with the EU? A gravity model approach. Economic Systems, v. 30, n. 2, p. 157-169, 2006. DOI: https://doi.org/10.1016/j.ecosys.2005.10.003

ARELLANO, M.; BOND, S. Some tests of specification for panel data: Monte Carlo evidence and an application to employment equations. The Review of Economic Studies, v. 58, n. 2, p.277-297, 1991. DOI: https://doi.org/10.2307/2297968

ARELLANO, M.; BOVER, O. Another look at the instrumental-variable estimation of error components model. Journal of Econometrics, v. 68, n. 1, p. 29-52, 1995. DOI: https://doi.org/10.1016/0304-4076(94)01642-D

AZEVEDO, A.F.Z. O efeito do MERCOSUL sobre o comércio: uma análise com o modelo gravitacional. Pesquisa e Planejamento Econômico, v. 34, n. 2, p. 307-340, 2004.

BAIER, S.L.; BERGSTRAND, J.H. Do free trade agreements actually increase members' international trade? Journal of International Economics, v. 71, n. 1, p. 72-95, 2007. DOI: https://doi.org/10.1016/j.jinteco.2006.02.005

BALDWIN, R.; TAGLIONI, D. Gravity for dummies and dummies for gravity equations. NBER Working Paper, n. 12516, 2006. DOI: https://doi.org/10.3386/w12516

BAXTER, M.; KOUPARITSAS, M.A. What determines bilateral trade flows? National Bureau of Economic Research, NBER Working Paper, n. 12188, Cambridge, 2006. DOI: https://doi.org/10.3386/w12188 
BENEDICTIS, L.; VICARELLI, C. Trade potentials in gravity panel data models. Journal of Economic Analysis E Policy, v. 5, n. 1, p. 1-33, 2005. DOI: https://doi.org/ $10.2202 / 1538-0653.1386$

BENEDICTIS, L.; VICARELLI, C. Trade potentials in gravity panel data models. Working Paper, n. 44, 2004. DOI: https://doi.org/10.2139/ssrn.506562

BERGSTRAND J.H. The generalized gravity equation, monopolistic competition, and the factor- proportions theory in international trade. The Review of Economics and Statistics, v. 71, n. 1, p. 143-153, 1989. DOI: https://doi.org/10.2307/1928061

BERGSTRAND J.H.. The gravity equation in international trade: some microeconomic foundations and empirical evidence. The Review of Economic and Statistics. v. 67, n. 3, p. 474-481, 1985. DOI: https://doi.org/10.2307/1925976

BITTENCOURT, G. M. Efeitos da instabilidade da taxa de câmbio no comércio setorial entre Brasil e seus principais parceiros comerciais. 2013. 73f. Dissertação (Mestrado em Economia Aplicada) - Universidade Federal de Viçosa, Viçosa - MG, 2013. DOI: https://doi.org/10.1590/1413-8050/ea503

BLUNDELL, R.; BOND, S. Initial conditions and moment restrictions in dynamic panel data models. Journal of Econometrics, v. 87, n. 1, p. 15-143, 1998. DOI: https:// doi.org/10.1016/S0304-4076(98)00009-8

BUN, M. J. G.; KLAASSEN, F.J. G. M. The Importance of Dynamics in Panel Gravity Models of Trade. Working Paper, n. 2002. DOI: https://doi.org/10.2139/ssrn.306100

CASTILHO, M. R.; LUPORINI, V. A elasticidade-renda do comércio regional de produtos manufaturados. Brasília: Comissão Econômica para a América Latina e o Caribe (CEPAL) / INSTITUTO DE PESQUISA ECONÔMICA APLICADA (IPEA). 2010.52p.

CORREAA, C.R. Impactos das notificações ao acordo de barreiras técnicas nas exportações de produtos químicos do Brasil. 2011. 55 f. Dissertação (Mestrado em Economia) - Universidade Federal de Viçosa, Viçosa - MG, 2011. DOI: https://doi.org/10.11132/rea.2011.504 
DEARDORFF, A. V. Determinants of bilateral trade: does gravity work in a neoclassical framework?. In: FRANKEL, J.A. (Ed.) The regionalization of the world economy. Chicago: University of Chicago Press. 1998. Cap 1, p. 7- 31.

EVENNET S.J.; KELLER, W. On theories explaining the success of the gravity equation. Journal of Political Economy, v. 110, n. 2, p. 281-316. 2002. DOI: https://doi.org/10.1086/338746

FASSARELA, L. M. Impactos das medidas técnicas e sanitárias nas exportações brasileiras de carne de frango. 2010. 86 f. Dissertação (Mestrado em Economia Aplicada). Escola Superior de Agricultura Luiz de Queiroz, Universidade de São Paulo, Piracicaba, 2010.

FONSECA, R.; AZEVEDO, M.S.; VELOSO, E. O potencial de comércio entre Brasil e Índia: Um Exame com Base nas Estruturas de Vantagem Comparativa. Brasília: Confederação Nacional da Indústria (CNI), 2005. 30 p.

FRANKEL, J.A., ROMER, D. Does trade cause growth? American Economic Review, v. 89, n. 3, p. 379-399, 1999. DOI: https://doi.org/10.1257/aer.89.3.379

GAP - GRUPO DE ANÁLISE E PREVISÕES. Exportações de Manufaturados: Limitações ao Crescimento. Conjuntura em Foco, v. 17, n. 4, p. 1 -9, 2012.

GRAUWE, P.; SKUDELNY, F. The impact of EMU trade flows. Review of World Economics, v. 136, n. 3, p. 381-402, 2001. DOI: https://doi.org/10.1007/BF02707286

GREENE, W.H. Econometric Analysis. $5^{\text {a }}$ ed., Prentice Hall, Upper Saddle River. 2003

HALVORSEN, R.; PALMQUIST, R. The interpretation of dummy variables in semilogarithmic equations. The American Economic Review, v. 70, n. 3, p. 474-475, 1980.

HELMERS, C.; PASTEELS, J., A gravity model for the calculation of trade potentials for developing countries and economies in transition, international trade center trade sim, technical report, UNCTAD - WTO, 2005. 
HELPMAN E.; KRUGMAN, P. Market structure and foreign trade: increasing returns, imperfect competition and the international economy. Cambridge: MIT Press. 1985. $271 \mathrm{p}$.

HUMMELS, D. Transportation costs and international trade in the second era of globalization. Journal of Economic Perspectives, v. 21, n. 3, p. 131-154, 2007. DOI: https://doi.org/10.1257/jep.21.3.131

KAROV, V. et al. A preliminary empirical assessment of the effect of phytosanitary regulations on US fresh fruit and vegetable imports. Milwaukee, AAEA Discussion Paper, n. 40345, 2009.

KIM, M.; CHO, G.; KOO, W. Determining bilateral trade patterns using a dynamic gravity equation. Agribusiness E Applied Economics Report, n. 525, p. 1-16, 2003.

KRUGMAN, P.; OBSTFELD, M. Economia Internacional. $8^{a}$ ed. São Paulo: Pearson. 2010. $798 \mathrm{p}$

KUME, H.; PIANI, G. Fluxos bilaterais de comércio e blocos regionais: uma aplicação do modelo gravitacional. Pesquisa e Planejamento Econômico, v. 30, n. 1, p. $1-22,2000$.

JESUS, L.A. O impacto da volatilidade cambial nas exportações brasileiras para o Mercosul: uma análise em painel dinâmico. 2010. 94 f. Dissertação (Mestrado em desenvolvimento econômico) - Universidade Federal do Paraná (UFPRP), Paraná, 2010.

LAI, H.; ZHU, S.C. The determinants of bilateral trade. Canadian Journal of Economics, v. 37, n. 2, p. 623-640, 2004. DOI: https://doi.org/10.1111/j.00084085.2004.00011.x

MARTINEZ- ZARZOSO, I.; FELICITAS, N. L. D.; HORSEWOOD, N. Are regional trading agreements beneficial? Static and dynamic panel gravity models. North American Journal of Economics and Finance, v. 20, n. 1, p.46-65, 2009. DOI: https://doi.org/10.1016/j.najef.2008.10.001

MATA, D.; FREITAS, R.E. Produtos agropecuários: para quem exportar? Texto para Discussão, n. 1321. Rio de Janeiro: IPEA, 2008. 29 p. DOI: https://doi.org/10.1590/S0103-20032008000200001 
MDIC - MINISTÉRIO DE DESENVOLVIMENTO, INDÚSTRIA E COMÉRCIO EXTERIOR / SECEX - SECRETARIA DE COMÉRCIO EXTERIOR. Exportações e importações, por setores e por países, 2012. Disponível em: $<\quad$ http://www.mdic.gov.br/index.php/comercio-exterior/estatisticas-de-comercioexterior/series-historicas >. Acesso em 12 ago 2012.

MDIC - MINISTÉRIO DE DESENVOLVIMENTO, INDÚSTRIA E COMÉRCIO EXTERIOR. Tabelas de Correlações de Códigos e Classificações. Disponível em: < http://www.mdic.gov.br/index.php/comercio-exterior/estatisticasde-comercio-exterior/base-de-dados-do-comercio-exterior-brasileiro-arquivos-paradownload >. Acesso em 12 mar. 2012.

PEREZ, R. N.; TRUGLIA. Applied econometrics using Stata. Working Paper. Harvard University, 2009.

PINTO, A.C.B. Ensaios sobre a dinâmica e os determinantes das exportações. 2011. 199 f. Dissertação (Mestrado em Economia) - Universidade Federal de Uberlândia, Uberlândia - MG, 2011.

SHEPOTYLO, O. Gravity with zeros: estimating trade potential of CIS. Social Science Research Network, 2009. DOI: https://doi.org/10.2139/ssrn.1347997

TINBERGEN, J. Shaping the world economy. New York: 20th Century fund, 1962.

WANG, C., WEI, Y.; LIU, X., Determinants of bilateral trade flows in oecd countries: evidence from gravity panel data models. World Economy, v. 33, n. 7, p. 894-915, 2010. DOI: https://doi.org/10.1111/j.1467-9701.2009.01245.x

ZIMMERMANN, B.A. Relação entre câmbio real e as exportações por intensidade tecnológica: uma análise de painel de dados para o Brasil. 2012, 71 f. Dissertação (Mestrado em Desenvolvimento Econômico) - Universidade Federal do Paraná, Paraná - PR, 2012.

Recebido em 24.05.17

Aprovado em 18.02.19 